\title{
Promoting conceptual change of learning sorting algorithm through the diagnosis of mental models: The effects of gender and learning style
}

\author{
WILFRED W. F. LAU, ALLAN H. K. YUEN \\ Faculty of Education, The University of Hong Kong, Hong Kong
}

\begin{abstract}
It has been advocated that pedagogical content knowledge as well as subject matter knowledge are important in improving classroom instructions. To develop pedagogical content knowledge, it is argued that understanding of students' mental representations of concepts is deemed necessary. Yet assessing and comparing mental model of each individual is very tedious and time consuming. This study attempted to use gender and learning style to associate mental models in learning sorting algorithm. The Gregorc Style Delineator (GSD) was used to measure learning styles of participants. Mental models were assessed using the Pathfinder Scaling Algorithm (PSA). Results indicated that females showed greater similarity in mental models than males and concrete learners also exhibited closer resemblance to the expert mental model than abstract learners. These suggest that gender and learning style can be meaningfully used to associate mental models in order to provide a group-based instead of individual-based diagnosis and thus promote conceptual change in learning.
\end{abstract}

Keywords: Improving classroom teaching; Pedagogical issues; Programming and programming languages; Secondary education; Teaching/learning strategies

\section{Introduction}

Over the years, research has provided evidence in support of the notion that pedagogical content knowledge as well as subject matter knowledge are important for improving classroom instructions. McCaughtry (2005) refers to pedagogical content knowledge as "knowing subject matter, pedagogy, curriculum and students" (p. 379) and argues that "teachers must know students' prior knowledge and modes of understanding" (p. 380). This view is shared by Diana (1993) who asserts that:

Teachers need to know more than just their subject. They need to know the ways it can come to be understood, the ways it can be misunderstood, what counts as understanding: they need to know how individuals experience the subject. (p. 3)

Yet traditional assessment procedures provide few cues as to how students understand or misunderstand in the course of their learning since emphasis is usually placed on the outcomes rather than the process. To remedy this problem, Reeves (2000) suggests the use of alternative techniques of assessment. One of these assessment techniques suggested is cognitive assessment which aims to measure students' higherorder thinking skills and this is accomplished commonly by externalizing "the relationships they have made among concepts and processes within a domain and to 
reveal the structure of their knowledge" (p. 107). This notion of the structure of knowledge can be referred to as mental model according to Staggers and Norcio (1993). However, assessing and comparing mental model of each individual is very tedious and time consuming. Also, mental model studies conducted in the past have been criticized for an over-dependence on the performance data of the users which could be problematic (Sasse, 1991). The present study aimed to use gender and learning style to associate mental models in learning sorting algorithm so as to provide a group-based diagnosis of mental models in order to promote conceptual change. To measure mental models, this study adopted the Pathfinder Scaling Algorithm (PSA) (Schvaneveldt, 1990) which is preferable to other conventional methods in which mental models are elicited per se without any reliance on performance tests.

\section{Learning style}

It is commonly held that individuals learn in significantly different ways. These individual differences have been studied extensively under the heading of learning style. Unfortunately, however, reaching a definitive definition of the notion of learning style is not obvious since different researchers tend to work in isolation and address different aspects of the subject of style. In other words, it is difficult to define learning style unequivocally. Perhaps the definition by Riding and Rayner (1998) is the most comprehensive. They describe learning style as "an individual set of differences that include not only a stated personal preference for instruction or an association with a particular form of learning activity but also individual differences found in intellectual or personal psychology" (p. 51).

The notion of learning style is further confused by the occasional use of terms such as "cognitive styles" and "learning strategies" interchangeably with "learning styles" in the literature. Yet there is no consensus as to whether they are really referring to the same concept. Messick (1994) defines cognitive styles as "characteristic modes of perceiving, remembering, thinking, problem-solving, and decision making, reflective of information-processing regularities that develop in congenial ways around underlying personality trends. They are inferred from consistent individual differences in ways of organizing and processing information and experience" (p. 122). Riding and Cheema (1991) point out that learning style is more concerned with the use of cognitive style in a practical learning situation while cognitive style is reserved more for academic purposes. They add that, as compared with the bipolar nature of cognitive style, learning style encompasses more elements, which are not mutually exclusive. This seems to suggest that cognitive style is in fact a component of learning style. However, there is empirical evidence showing that learning style and cognitive style may be two independent constructs (Sadler-Smith, 2001). Another problematic term associated with learning style is "learning strategies". A learning strategy is understood as "a set of one or more procedures that an individual acquires to facilitate the performance on a learning task. Strategies will vary depending on the nature of the task" (Riding \& Rayner 1998, p. 80). On the other hand, learning style of an individual is more inherent to himself or herself and relatively stable over time (Loo, 1997). 
One intriguing aspect of learning style concerns its nature. As Riding and Cheema (1991) argue, cognitive/learning styles have been traditionally viewed as either a structure or a process or both and these different views have different implications for the educational setting. Cassidy (2004) discusses the "state-or-trait" debate on learning style and provides a more workable explanation: "a style may well exist in some form, that is it may have a structure, but that structure is, to some degree, responsive to experiences and the demands of the situation (process) to allow change and to enable adaptive behaviour" (p. 421). Nonetheless, in this study, learning style is understood as innate individual differences in terms of perceiving and processing information.

\section{Mental model}

The theory of mental model describes how individuals interact with the world cognitively. Yet defining the term "mental model" has been a subject of controversy in the literature. Doyle and Ford (1998) remarked that "available definitions are typically brief, overly general, and vague, and different authors offer definitions that markedly disagree on centrally important features of mental models" (p. 21). Despite this, the definitions by Gentner and Stevens (1983) and Johnson-Laird (1983) are widely quoted as references. Norman (in Gentner \& Stevens 1983, p. 7) described mental models as follows: "In interacting with the environment, with others, and with the artefacts of technology, people form internal, mental models of themselves and of the things with which they are interacting. These models provide predictive and explanatory power for understanding the interaction." He further notes that mental models are incomplete, inconsistent, unstable, inaccurate, and parsimonious. Johnson-Laird (1989) defines a mental model as follows:

A mental model can be defined as a representation of a body of knowledge - either long-term or short-term - that meets the following conditions: 1. Its structure corresponds to the structure of the situation that it represents. 2. It can consist of elements corresponding only to perceptible entities, in which case it may be realized as an image, perceptual or imaginary. Alternatively it can contain elements corresponding to abstract notions; their significance depends crucially on the procedures for manipulating models. 3. Unlike other proposed forms of representation, it does not contain variables... In place of a variable...a model employs tokens representing a set of individuals. (p. 488)

There are in fact underlying differences in these two definitions. As pointed out by Greca and Moreira (2000), the definition by Gentner and Stevens (1983) represents an instructional approach which aims to provide "knowledge about the physical phenomena and, particularly, about mechanical and technological devices people develop" (p. 2) while that by Johnson-Laird (1983) represents a theoretical approach which attempts to "offer a unified and explanatory theory of distinctive cognitive phenomena, such as deductive reasoning and discourse comprehension" (p. 2).

In the literature, mental model has been described in different ways as "internal representation that the learner forms of the target system" (Papastergiou, 2005, p. 343), "mental representations to reason about, explain, and predict the behavior of external 
systems" (Ramalingam, LaBelle, \& Wiedenbeck, 2004, p. 172), "complex schemas comprised of components and the relationships among them" (Brandt, 2001, p. 82), knowIedge about a system, its component parts and how they influence one another (Fein, Olson, \& Olson, 1993), "organized structures consisting of objects and their relationships" (Staggers \& Norcio 1993, p. 591), and "a person's understanding of the environment" (Shih \& Alessi 1993, p. 157). Another related term is "conceptual model". It should be noted that a conceptual model is an appropriate representation of the target system created by researchers, teachers, designers, scientists, and engineers with the intention of facilitating understanding and teaching (Gentner \& Stevens, 1983; Greca \& Moreira, 2000). On the other hand, a mental model is constructed individually and recursively through interaction with the external world.

Notwithstanding the discrepancies in the definitions described above, in general, mental model can be understood as a cognitive structure that forms internal representation of objects of the external reality. It is a working model that enables individuals to understand and explain the phenomena, to make predictions and inferences, and to make decisions.

\section{The Gregorc Style Delineator}

The Gregorc Style Delineator (GSD) (1982) was used to measure the participants' learning styles in this study. This instrument and the reasons for using it are described below. According to Gregorc, the GSD was developed from data gathered through observations, taped interviews, and written protocols employing the phenomenological methodology which allows the collection and analysis of data of the "cognitive subjective perspective of the individual who was behaving, and the individual's feelings prior to, during, and subsequent to the behavior" (Gregorc 1984b, p. 52). On analyzing the data, two sets of opposing bipolar relationships became evident, identified as primarily the basic dimensions of perception and ordering. With respect to perceptual abilities, the two qualities identified were abstractness and concreteness while in terms of ordering abilities, the two qualities identified were sequence and randomness. This formed the basis of what Gregorc called the Mind Styles Model. This model suggests that the human mind has channels through which information is received and expressed most efficiently and effectively. Gregorc further introduces the term "mediation abilities" to refer to a person's "power, capacity, and dexterity to utilize these channels" (Gregorc, 1982, p. 5) and defines the term "style" as the external manifestation of an individual's mediation abilities. From these two mediation abilities, each of which has two qualities, four mediation channels of mind styles can be formed: Concrete Sequential (CS), Concrete Random (CR), Abstract Sequential (AS), and Abstract Random (AR). Abstract learners tend to comprehend and process information with little reference to the physical reality. By contrast, concrete learners rely on their physical senses for an understanding of phenomena. Sequential learners perceive and organise data in a linear fashion while random learners are able to reason in a non-linear and multi-dimensional fashion.

Schulz (1993) identified a number of advantages of using the GSD as the instrument for studying learning styles including simplicity of administration and 
completion. These reasons are very important for this study since participants were secondary school students. They need to work with a relatively easy and self-explanatory instrument or otherwise they would not be likely to take the instrument seriously. To score in the GSD, one needs to rank four words at a time on a scale of 1 to 4 , with 4 representing the most suitable description of oneself and 1 representing the least suitable one. Each word in the four-word group corresponds to one of the four channels. The scores for ten four-word groups for each channel are then totalled to determine the total scores in the four mediation channels. Thus, the possible scores in each channel can range from 10 to 40 . Scores between 27 and 40 indicate a strong orientation towards that learning style and scores from 10 to 15 indicate a weak orientation. The highest score determines the dominant learning style and by the same token the lowest score determines the weakest learning style. However, it should be noted that there is no "pure" type of learning style and a combination of types is likely.

\section{The Pathfinder Scaling Algorithm}

Mental model has been assessed using various methods including think-alouds and verbal protocols, online protocols, and performance data (Sasse, 1991). Yet Sasse commented that the results of such methods are often problematic because of the restrictive and artificial experimental scenarios, an insufficient range of information collected, and small samples often focused on novice users. As an alternative method, Jonassen (1995) suggests that structural knowledge methods can be used to develop representations of mental models. Structural knowledge is understood as "the knowledge of the structure of concepts in a knowledge domain" (p. 184). Using these methods, the concepts, as well as their relations with the others, are represented as a network, which depicts the mental model of the subject concerned. Out of all of these methods, the PSA (Schvaneveldt, 1990) was selected to assess mental models in this study with regard to the present learning context and research aims. First, it provides a quantifiable concept map which permits comparisons with other learners and experts and measurement of changes in understanding over time (Reese, 2003). In fact, unlike other knowledge representation tools such as tree construction task, cognitive maps, and verbal tests, this technique can be used to identify "a consensus understanding of a group" (Jonassen, Beissner, \& Yacci, 1993, p. 76) through averaging proximity data of the same group and this suits our purpose of making between-group comparisons. Second, the network structure can reveal local relations among concepts which are psychologically meaningful compared with other multi-dimensional scaling representations (Cooke, 1992; Cooke \& Schvaneveldt, 1988 ) and it is our intent to elicit students' conceptual understanding in learning sorting algorithm in order to promote conceptual change. These justify the use of this knowledge representation tool in this study.

By means of the PSA, which is implemented using the PCKNOT software (http://interlinkinc.net/index.html), a network can be built of the concepts of the problem domain under consideration and this is called the Pathfinder Network (PFNET). In this network, the nodes and links represent the concepts and relations between the concepts respectively. To construct such a network, subjects are asked to give a rating from 1 to 9 
for every possible pair of concepts according to the relatedness of the concepts in the pair. These ratings are then converted into proximities, which are used to construct the network. Also, a weight, corresponding to the strength of the relation, is given to each

link. In theory, $n$ concepts need $\frac{n(n-1)}{2}$ pair wise comparisons. In order to compare

PFNETs quantitatively, similarity measures can be evaluated with reference to a referent structure provided by an expert. In general, there are three such kinds of measures: PRX, $\mathrm{C}$, and GTD. PRX is simply the correlation of raw proximities. $\mathrm{C}$ is a set-theoretic method, which computes the ratio of nodes that are common to the nodes in both networks in the neighbourhood of each node and averages the results across all the nodes to obtain an overall index of similarity. GTD is a graph-theoretic method, which correlates the distances between the nodes in two networks. Further illustration of how $\mathrm{C}$ and GTD are calculated can be found in the paper by Goldsmith, Johnson, and Acton (1991). It is interesting to note that these three systems of measurement seem to have different predictive powers for academic performance. In fact, Goldsmith et al. demonstrate that of the three indicators of similarity, $\mathrm{C}$ is the most predictive of final course points $(r=0.74)$. This is followed by GTD $(r=0.66)$ and then PRX $(r=0.61)$. This pattern still exists even when other indicators are held constant.

\section{Mental model and computer programming}

To date, relatively few studies have reported the effects of gender and learning style on mental model. One study by Van Engers (2001) found that there was a learning style effect on knowledge structures and that the effect was persistent in a group of 30 subjects working in an audit department. In particular, in the mental models of 15 auditrelated concepts, comprehension learners thought that planning was the most important concept compared with versatile and operation learners. Operation and versatile learners thought that file was the most important concept compared with comprehension learners. However, Van Engers used the Pask Smugglers test as the learning style instrument and also the problem domain was about auditing, not computer programming. Most other studies have tended to focus on how the possession of a viable mental model influences programming performance. Bayman and Mayer (1988) demonstrated that mental models have a significant effect on performance in a programming test. In their study, subjects who had better mental models, as measured by the scores in another test, were able to solve correctly $75 \%$ of the problems in the programming test. By contrast, subjects having poorer mental models could only solve $42 \%, \mathrm{~F}(1,42)=49.35, \mathrm{p}<0.001$. In another study, Shih and Alessi (1993) showed that using conceptual models to teach code evaluation produces significantly better results in code evaluation and code generation than those who were taught without conceptual models. They argue that novices, with the aid of conceptual models, develop better mental models that help to improve their performance. Ramalingam et al. (2004) showed that among a number of performance predictors, mental model, as measured by performances in program comprehension and program recall, directly affects the students' final course grade. 
Ma, Ferguson, Roper, and Wood (2007) investigated mental models of a value and reference assignment concerning programming concepts among a group of first-year university students. A mental model was considered to be viable if it satisfied two conditions: (1) It matches the model in which a programming concept actually works (appropriate) and (2) It has to match the actual model at all times (consistent). Students were classified into three groups, namely a consistently appropriate group, a consistently inappropriate group, and an inconsistent group according to the viability of their mental models. Results indicated that students in the consistently appropriate group outperformed the other two groups in the evaluation of both value and reference assignments both during the in-course assessments and in the final examination.

\section{Research questions}

Given the importance of mental model in influencing programming performance and that relatively little is known about the effects of gender and learning style on mental model, this study aimed to investigate whether gender and learning style can be used to associate mental models meaningfully in order to provide a group-based diagnosis of mental models with the ultimate aim of promoting conceptual change in learning sorting algorithm. Specifically, the two research questions are:

1. Are there any significant differences in the mental models of programming students across gender and learning style?

2. Is it possible to identify the misconceptions of students quantitatively across gender and learning style?

\section{Method}

\subsection{Participants}

Participants in this study were either Secondary 4 (Grade 10) or Secondary 5 (Grade 11) students who had opted for the elective module A (Algorithm and Programming) in the Computer and Information Technology subject and were drawn from nine secondary schools in Hong Kong. They had learnt the bubble-sorting algorithm by the time of the data collection. Sorting algorithm was selected because it is fundamental to the understanding of more advanced programming concepts and yet difficult to students at secondary education level (Geller \& Dios, 1998 ; Kordaki, Miatidis, \& Kapsampelis, 2008). One hundred and thirty-one students took part in this study on a voluntary basis at the invitation of their teachers. Fifty-two of them were female $(39.7 \%)$ and 79 were male $(60.3 \%)$. Their ages ranged from 14 to 19 . The mean age of females was 16.42 (s.d. $=$ 0.11 ) while the mean age of males was 16.01 (s.d. $=0.07$ ). In terms of the dominant learning style, CS was the major style for females (34.6\%) followed by AS (30.8\%) while the major style for males was CR (41.8\%) followed by CS (29.1\%). The learning style of 
one female participant was not classified, which means that her scores in the GSD were equal in two or more scales and could not be resolved ( $\mathrm{CS}=25, \mathrm{AS}=25, \mathrm{AR}=25, \mathrm{CR}=25)$. In other cases where same scores occurred in two scales, style was assigned by considering the scores in other scales. For instance, if an individual obtained the following scores $(\mathrm{CS}=21, \mathrm{AS}=27, \mathrm{AR}=27, \mathrm{CR}=25)$, he or she was classified as an $\mathrm{AR}$ learner since the CR score was higher than the CS score.

\subsection{Instrument}

Gregorc (1984a) reported the Cronbach's alpha coefficients of the four scales of the GSD from 0.83 to 0.93 . Joniak and Isaksen (1988) found that the alpha coefficients were from 0.23 to 0.66 . O'Brien's (1990) results indicated that alpha coefficients ranged from 0.51 to 0.64 , which is similar to the values found in this study $(0.40$ to 0.66$)$. Although they are substantially lower than the coefficients originally reported by Gregorc, it may be justifiable to say that "separate items did not serve well as measures of their respective latent variables, jointly they may have provided adequate measurement scales for the four constructs" (O'Brien 1990, p. 365). Also, individuals may not always have a clear idea of how they actually behave and can be influenced by problems such as moods, illness or stress (Ross, Drysdale, \& Schulz, 2001) and these may affect reliability of the instrument. Nonetheless, there is further evidence to support the use of the GSD in academic settings. Seidel and England (1997) concluded that "the reliability of the Gregorc learning styles delineator is sufficient to investigate the construct validity in terms of its use in the classroom" (pp. 10-11) and Butler and Pinto-Zipp (2005) also concluded that "the strength of the GSD outweighs the weakness and the literature supports the use of the GSD in learning styles research" (p. 202).

\subsection{Procedure}

The data collection process was carried out entirely online. In the first instance, participants were asked to provide some personal information such as age and gender. Then they were asked to complete the GSD instrument, which would take about 4 minutes. Before they actually did this, they were provided with a number of directions and suggestions related to the instrument. One of these was that it was very important that the participants judged the relative value of the words in each group using their real self as the reference point, not the one at home or in school. Also, they were asked to rank the words in each group using their first impression. Next, the participants spent 15 minutes completing a relatedness-rating task on sorting-related concepts in order to assess their mental models. For this study, 11 concepts (computer, program, algorithm, sorting, arrange, correct order, pass, compare, swapping, ascending, and descending) relevant to the sorting algorithm were selected based on three commonly used textbooks in Hong Kong (Chan, 2004; Fung, Lau, \& Kai, 2003; Woo, Shiu, \& Wang, 2003). For these 11 concepts, a total of 55 ratings had to be done. In Hong Kong, while many teachers tend to explain sorting algorithm using a variety of methods such as pseudo-code, flowchart, 
algorithm visualization, and animation, it is believed that students have some experience in using concept mapping tools as a means to develop their creativity in humanities subjects (Hong Kong Curriculum Development Council, 2002, p. 50). As such, students should have established some degree of familiarity when they are asked to construct concept maps. More importantly, clear instructions were provided to students on how to construct PFNETs.

\subsection{Referent structure}

In choosing experts for providing the referent structures, the following criteria were used: first, the expert must possess a degree in Computer Science or related discipline and second, the expert must have at least 6 years of either practising or teaching computer programming. Given that a university degree usually takes 4 years to complete and that it is commonly agreed that a 10-year period is required to reach the level of an expert (Winslow, 1996), it is justifiable to use the above criteria to identify experts. Based on the above criteria, three experts agreed to complete the rating task to provide their referent structures so that similarity measures could be calculated. The first expert was a computer officer with 14 years of experience in system development working in a university faculty. He holds a Bachelor's degree in Computer Science, a Master's degree in Management of Information Technology, and another Master's degree in Business Administration. The second expert was an assistant computer officer working in the same faculty as the first expert. She had a Bachelor's degree in Computer Science and 7 years of programming experience. The third expert was a secondary school programming teacher with 10 years of teaching experience. He also holds a Master's degree in Computer Science.

In a study to investigate the predictive validity of similarity measures, Acton, Johnson, and Goldsmith (1994) concluded that individual experts are highly variable in terms of their predictive power and variability can be largely reduced by averaging the ratings of experts. Yet there may exist an excellent expert whose model is highly predictive of performance measures across different groups of students. As such, a number of combinations of referent structures were examined. The similarity measure $\mathrm{C}$ was chosen to correlate with the performance measures since it has the highest predictive power among the others as reported in the literature. Programming performance was assessed by a test that covered four types of knowledge: declarative knowledge (DK), procedural knowledge (PK), conditional knowledge (CK), and strategic knowledge (SK). Detail concerning the test can be found in an article by (intentionally omitted). Correlations between $\mathrm{C}$ of the first expert (EXP1), the second expert (EXP2), the third expert (EXP3), the average ratings of the first and second experts (AVE12), the average ratings of the second and third experts (AVE23), the average ratings of the first and third experts (AVE13), the average ratings of the three experts (AVE123), and the four performance measures (DK, PK, CK, SK) are compared in Table 1.

$<<$ Insert Table 1 here $>>$

Results showed that experts did vary in their predictive ability. It is clear that EXP2 predicted three of the performance measures DK, PK, and CK significantly while 
the others predicted no, one or two measures. In the literature, there is research that utilized a single expert network (Nash, Bravaco, \& Simonson, 2006) or an averaged expert network (Trumpower \& Goldsmith, 2004) as a referent structure. However, Acton et al. (1994) argue that "the validity of a referent structure is related to its ability to predict exam performance in computer programming courses" (p. 304) and thus it is legitimate to select an expert referent based on its predictive ability on programming performance. Therefore, the referent structure provided by the second expert was chosen as the expert model for comparison purpose in this study. While acknowledging that the expert choice was made in a rational way, it does show that caution should be taken when making generalizations in view of disparity among experts.

\section{Results}

\subsection{MANOVA of mental models}

To answer the first research question, a hypothesis was tested to see whether there were significant differences in mental models of programming students across gender and learning style. The null hypothesis stated that there were no differences between mental models for either gender or dominant learning style or their interaction. A 2 (Male, Female $) \times 4(\mathrm{CS}, \mathrm{AS}, \mathrm{CR}, \mathrm{AR})$ MANOVA was performed on three dependent variables PRX, C, and GTD. Both gender and dominant learning style were the between-subject variables.

In order to provide an overall representation of mental models of the different learning style groups and genders, the proximity data of the same groups were averaged and correlated with the referent structure provided by the single expert for each group. Table 2 shows the three similarity measures of the four learning style groups of each gender after averaging. For males, in PRX, the CR group had the highest similarity score followed by the CS group. In C, the CS group had the highest similarity score followed by the AS and AR groups. In GTD, the AS group had the highest similarity followed by the AR group. No definite pattern was observed for the male groups. For females, it can be seen that, regardless of the measures used, the sequential group (AS or CS) always showed higher similarity than the random group (AR or CR). Differences in the three similarity measures within groups are likely to be due to the fact that these measures appear to capture different aspects of configural similarity of PFNETs.

$<<$ Insert Table 2 here $>>$

Figures 1 to 9 show the PFNETs of the single expert and of the four learning style groups of each gender after averaging. These provide useful visual representations of mental models and facilitate qualitative comparisons between different groups and genders. Figure 1 is the PFNET provided by the expert. There are 31 links in her network and it can be said to be very sorting-oriented. There are a few nodes which have multiple links: pass (10), swapping (8), compare (8), and sorting (6). The concept "pass" is linked to all of the other 10 concepts. The concept "swapping" is linked to other important concepts such as sorting, compare, and pass. The concept "compare" is linked to other 
important concepts such as pass and swapping. The concept "sorting" is related to other important concepts such as pass, compare, and swapping. Overall, therefore, the PFNET identifies the correct relations in a sorting algorithm.

$$
<<\text { Insert Figure } 1 \text { here }>>
$$

In Figure 2, the PFNET of the male CS group contains 12 links. The two nodes with the most links are arrange (4) and sorting (4). Yet there are some concepts that are not linked correctly. For instance, the concepts in the pairs of sorting-pass and sortingalgorithm are quite distant from each other. In Figure 3, the PFNET of the male AS group contains 10 links. The nodes with the most links are: correct order (3), swapping (3), and compare (3). Again some concepts are not linked properly. For instance, the concepts in the pairs of sorting-pass and sorting-compare are quite distant from each other. In Figure 4, the PFNET of the male CR group contains 12 links. The two nodes with the most links are correct order (5) and program (4). Yet there are some concepts that are not linked correctly. For instance, the concepts in the pairs of sorting-swapping and pass-swapping are quite distant from each other. Figure 5 shows the PFNET of the male AR group. There are 10 links in the network. The concept with the most links is sorting (5). However, the important concepts are not connected as expected. For instance, the concepts in the pairs of sorting-swapping and pass-compare are quite distant from each other. In general, the PFNETs of the four male groups contain about 10 links between concepts and there are so few links that important concepts are not linked as expected. The topology of the networks resembles a star with occasional branching and/or loop, indicating a lack of expertise to determine how the nodes should be properly linked.

$$
\begin{aligned}
& <<\text { Insert Figure } 2 \text { here }>> \\
& <<\text { Insert Figure } 3 \text { here }>> \\
& <<\text { Insert Figure } 4 \text { here }>> \\
& <<\text { Insert Figure } 5 \text { here }>>
\end{aligned}
$$

For females, as shown in Figure 6, the PFNET of the female CS group contains 10 links. The nodes with the most links are: sorting (5), swapping (3), and program (3). This PFNET is considered to be quite sorting-oriented. However, some important concepts are not linked as expected. For instance, the concepts in the pairs of ascending-arrange and descending-arrange are quite distant from each other. In Figure 7, the PFNET of the female AS group contains 10 links. The node with the most links is arrange (3). The concepts are linked in a more or less linear fashion but important concepts are not linked as expected. For instance, the concepts in the pairs of sorting-pass and swapping-pass are quite distant from each other. In Figure 8, the PFNET of the female CR group contains 13 links. The nodes with the most links are: computer (4), algorithm (3), program (3), descending (3), and sorting (3). Important concepts are not linked as expected. For instance, the concepts in the pairs of sorting-arrange and compare-pass are quite distant from each other. Finally, Figure 9 shows the PFNET of the female AR group. There are 10 links found in this network. The three nodes with the most links are: program (3), compare (3), and descending (3). However, these are not considered to be the most important concepts in the sorting algorithm. Also, the fact that the concepts in the pairs of compare-swapping and pass-compare are quite far apart from each other suggests that they are not highly related. In general, the PFNETs of the four female groups contain 
about 10 links between concepts and here important concepts are not linked as expected due to the small number of links. Again, a similar topology of networks is observed when compared with the male groups and this seems to be typical among novices.

$$
\begin{aligned}
& <<\text { Insert Figure } 6 \text { here }>> \\
& <<\text { Insert Figure } 7 \text { here }>> \\
& <<\text { Insert Figure } 8 \text { here }>> \\
& <<\text { Insert Figure } 9 \text { here }>>
\end{aligned}
$$

One female participant whose scores were equal in all four scales was excluded from the analysis. Utilizing Wilks' lambda criterion, no significant main effect was found for gender $(p=0.129)$ and dominant cognitive style $(p=0.421)$. There was also no significant interaction effect between gender and dominant learning style $(p=0.718)$. Inspection of the means of the similarity measures for the four learning style groups indicates that in general, concrete learners had a higher degree of similarity as compared with abstract learners. Therefore, another 2 (Male, Female) $\times 2(\mathrm{C}, \mathrm{A})$ MANOVA was performed on three dependent variables, PRX, C, and GTD. The null hypothesis stated that there were no differences between the mental models for either gender or the perception dimension or their interaction. The styles CS and CR were collapsed as C while the styles AS and AR were collapsed as A. Both gender and the perception dimension were the between-subjects variables. Descriptive statistics of the similarity measures by gender and the perception dimension are shown in Table 3.

$$
<<\text { Insert Table } 3 \text { here }>>
$$

The Wilks' lambda criterion revealed a significant main effect for gender, $\mathrm{F}(3$, $124)=2.748, p<0.05$, partial $\eta^{2}=0.062$ and the perception dimension, $F(3,124)=$ $3.558, p<0.05$, partial $\eta^{2}=0.079$ but no significant interaction effect $(p=0.818$ ) (see Table 4). The values of partial $\eta^{2}$ indicated that there was a mild association between gender and the perception dimension on the combined dependent variables. Therefore, the null for this hypothesis was rejected.

\section{$<<$ Insert Table 4 here $>>$}

Univariate analyses were performed on the main effect of gender and the perception dimension on each of the individual dependent variables. Gender differences existed in PRX, $\mathrm{F}(1,126)=5.664, \mathrm{p}<0.05$, partial $\eta^{2}=0.043, \mathrm{C}, \mathrm{F}(1,126)=7.240, \mathrm{p}<$ 0.01 , partial $\eta^{2}=0.054$, and GTD, $\mathrm{F}(1,126)=7.510, \mathrm{p}<0.01$, partial $\eta^{2}=0.056$. Perception dimension differences existed in $\mathrm{PRX}, \mathrm{F}(1,126)=6.032, \mathrm{p}<0.05$, partial $\eta^{2}=$ 0.046 and GTD, $\mathrm{F}(1,126)=9.739, \mathrm{p}<0.01$, partial $\eta^{2}=0.072$ but not in $\mathrm{C}, \mathrm{F}(1,126)=$ 3.294, $\mathrm{p}=0.072$. Post hoc comparisons using Tukey's HSD showed that the mental models of female students were more similar to those of the expert compared with those of male students for all the similarity measurements. Concrete students exhibited a higher similarity in the mental models than abstract students as measured by PRX and GTD.

\subsection{Misconceptions among the four learning style groups by gender}


To answer the second research question, it is most important to identify any misconceptions of different groups as compared to those in the model of the expert. The criteria for classifying a concept as being misunderstood is based on the median split in the difference values for the 11 concepts and the four learning style groups (Cooke \& Schvaneveldt, 1988). The following explains how the difference values are calculated. For each target concept in the domain, if a direct link exists between the target concept and another concept, a value of 1 is assigned to the corresponding value of the difference vector of the target concept, otherwise 0 is assigned. This is done for all of the concepts and for each concept as the target concept. A matrix of 10 (concept pairs) $\times 11$ (concepts) is created for a PFNET. The matrices of the same group are added and all of the elements are converted into percentages. To compare the differences between any groups, one group matrix is subtracted from another one to obtain a difference matrix and a difference value for each concept is computed by summing the absolute difference of all the elements in the corresponding vector of the difference matrix.

Concepts associated with difference values lower than the split value are considered to be well defined and those with difference values higher than the split value are regarded as mis-defined. Results of the classification of mis-defined concepts for the four learning style groups of each gender are shown in Tables 5 and 6.

$$
\begin{aligned}
& <<\text { Insert Table } 5 \text { here }>> \\
& <<\text { Insert Table } 6 \text { here }>>
\end{aligned}
$$

For males, the mean percentage differences per concept (standard deviations in parentheses) for the four groups were $42.06 \%$ (19.27\%) for CS, $46.52 \%(16.18 \%)$ for AS, $39.17 \%(16.17 \%)$ for $\mathrm{CR}$, and $47.77 \%(12.34 \%)$ for AR. The number of mis-defined concepts for the four groups was 3 for CS, 7 for AS, 3 for CR, and 10 for AR. The differences between the groups were significant, $\chi^{2}(3)=12.663, p<0.01$. For females, the mean percentage differences per concept (standard deviations in parentheses) for the four groups were $34.04 \%$ (18.47\%) for CS, $41.59 \%$ (18.79\%) for AS, $38.18 \%$ (28.48\%) for CR, and $41.36 \%$ (15.14\%) for AR. The number of mis-defined concepts for the four groups was 3 for CS, 6 for AS, 5 for CR, and 8 for AR. However, the differences between the groups were not significant, $\chi^{2}(3)=4.727, p=0.193$.

\section{Discussion}

Significant differences were found between the similarity measures of learners of different genders and learning styles. Mental models of female students were more similar to those of the expert than were those for male students in all the similarity measurements. One possible explanation of this is that the expert is in fact female. Other reasons for such a phenomenon merit further investigation. Concrete students showed a higher similarity in mental models than abstract students and the perception dimension of the GSD seems to be significant in the mental model construction. This is congruent with the findings by Van Engers (2001) that differences in learning styles cause differences in knowledge structures as measured by node centrality and coherence of the PFNET despite differences in the learning style instrument used and the problem domain. 
According to Gregorc (1982), concrete learners grasp and mentally register data through the use of their physical senses and this quality helps them to understand the sorting algorithm better since they can physically approach the concept using various metaphors. This idea is also supported by López, Myller, and Sutinen (2004) who argue in favour of the efficacy of combining traditional algorithm visualization with hands-on robots to "bring algorithms into the real physical world where students can even touch the data structures during the execution" (p. 377). On the other hand, this novel approach to reducing abstraction can be appealing to abstract learners. As abstract learners tend to grasp and mentally visualize data through the use of reason, to help these learners, teachers may 'stretch' their style by concretizing the sorting algorithm with the use of robots as physical metaphors and re-examine the mental models of students after this intervention to see whether the learners have come to think more like an expert. This is an area that requires further research.

In today's education reform, there is a call for the development of higher-order thinking skills and conceptual understanding through developing knowledge structure is vital for such an initiative. Jonassen and Gabrowski (1993) argue that "explicit awareness of those inter-relationships and the ability to personally describe those relationships is a fundamental component in prior knowledge and an essential component in higher order thinking" (p. 433). It is not uncommon to find that students bring their own preconceptions of learning to classes and in order to promote conceptual change, the most important first step is in “(a) uncovering students' preconceptions about a particular topic or phenomenon, and (b) using various techniques to help students change their conceptual framework" (Bruce \& McMahon, 2002, p. 11). Accompanying changes in teaching strategies include "(a) maintaining student interest through hands-on instruction and relevant content, and (b) an approach which integrates context, process and reflection with respect to the content" (p. 10).

Traditionally, PSA was seen as one of the techniques for structural knowledge elicitation and was used widely in the education setting to identify expertise and assess changes in knowledge structure. However, it has been commented that "results of structural assessment do not suggest instructional or remediation strategies for addressing trainee weakness" (Davis, Curtis, \& Tschetter, 2003, p. 202). This study shows that gender and learning style can be meaningfully used to associate mental models so as to provide a group-based rather than an individual-based diagnosis, which is considered to be very time-consuming. In practice, teachers can adopt the method proposed in this study to help them to identify and rectify any misconceptions by students of different genders and learning styles. Specifically, once mis-defined concepts have been identified, for each learning style group and gender, teachers may compare the linkage of the mis-defined concepts in the group with the expert's PFNET and ask students in that group why they connected the concepts in that way. Teachers could explain to the group what they would regard as the correct relations between the concepts and students would then be required to construct their PFNETs again. For instance, for the male AR group, swapping is one of the mis-defined concepts (Table 5). From Figure 5, swapping is linked to computer and pass only. However, in Figure 1, the same node of the expert network is connected with pass, computer, compare, algorithm, sorting, correct order, arrange, and ascending. Teachers may then ask students in this group for the discrepancy and explain to them 
what they would view as the correct relations. This procedure is repeated for all the other mis-defined concepts, which is followed by a re-construction of PFNETs.

This practice of identifying misconceptions and effecting conceptual change is also supported by Uzuntiryaki and Geban (2005) in a study of students' conceptions of solutions in Chemistry. In their study, students were presented with texts that explicitly addressed their misconceptions with the aim of creating conceptual conflicts and teachers tried to explain what had gone wrong and had given rise to those misconceptions. Students were then asked to explain the consequences of adding salt to water. They experienced conflicts as they attempted to explain their conceptions. Finally, they had to construct concept maps with a predefined set of terms to show their level of understanding. Results indicated that students who received this treatment produced a better performance in a related concept test and reported a more positive attitude towards science than students who received the traditional instruction. Clearly, it would be worthwhile to test the generality of the research findings in other different contexts, particularly when the processes of map construction and re-construction/elaboration under reflection are still under-researched.

However, the success of this cognitive conflict strategy hinges on a number of contextual factors related to the learners, the social context in which learning takes place and teachers themselves (Limón, 2001), and teachers should be aware of the influence of these factors when implementing this strategy. Taking into consideration the above factors, it is expected that this strategy could help dispel students' misconceptions, enhance conceptual understanding of students, and eventually help develop higher-order thinking skills among students.

\section{Limtations and future work}

First, it is necessary to identify the confounding variables in this study and replicate the present research with control of these variables. Second, some other instruments of measuring learning style could be examined in future studies. In particular, instruments of well-researched and established psychometric properties are likely to benefit the analysis and interpretation of research outcomes. Third, computation of the similarity measures relies on the choice of the expert referent. To achieve prediction consistency of experts, a range of experts in programming could be recruited to compare their variability in terms of predictive power of performance measures. These experts could include computer programmers, high school teachers, and university professors. Alternatively, a referent-free approach using the coherence measure provided by the PSA is also viable. Finally, this study is cross-sectional and collected data on computer programming students at a certain time. A longitudinal study could be undertaken to understand learning sorting algorithm as a developmental process.

\section{Conclusions}


This study attempted to examine whether gender and learning style can be used to associate mental models in learning sorting algorithm. Results indicated that mental models of females were more similar to those of the expert referent structure and that concrete learners had a higher similarity in their mental models with the expert one than abstract learners. This suggests that gender and learning style, as measured by the GSD, can be meaningfully used to associate mental models to provide a group-based diagnosis of misconceptions in order to promote conceptual change and this idea is in line with the notion of cognitive diagnostic assessment (Nichols, 1994) in identifying misconceptions in learning and capturing any changes in knowledge structure when learning occurs.

\section{References}

Acton, W. H., Johnson, P. J., \& Goldsmith, T. E. (1994). Structural knowledge assessment: Comparison of referent structures. Journal of Educational Psychology, 86(2), 303-311.

Bayman, P., \& Mayer, R. E. (1988). Using conceptual models to teach BASIC computer programming. Journal of Educational Psychology, 80(3), 291-298.

Brandt, D. S. (2001). Information technology literacy: Task knowledge and mental models. Library Trends, 50(1), 73-86.

Bruce, C., \& McMahon, C. (2002). Contemporary developments in teaching and learning introductory programming: Towards a research proposal. Brisbane, Queensland: Queensland University of Technology, Faculty of Information Technology.

Butler, T. J., \& Pinto-Zipp, G. (2005). Students' learning styles and their preferences for online instructional methods. Journal of Educational Technology Systems, 34(2), 199-221.

Cassidy, S. (2004). Learning styles: An overview of theories, models, and measures. Educational Psychology, 24(4), 419-444.

Chan, R. W. N. (2004). Computer and information technology C programming. Hong Kong: Radian Publishing Company.

Cooke, N. J. (1992). Predicting judgment time from measures of psychological proximity. Journal of Experimental Psychology: Learning, Memory, and Cognition, 18(3), 640-653.

Cooke, N. J., \& Schvaneveldt, R. W. (1988). Effects of computer programming experience on network representations of abstract programming concepts. International Journal of Man-Machine Studies, 29(4), 407-427.

Davis, M. A., Curtis, M. B., \& Tschetter, J. D. (2003). Evaluating cognitive training outcomes: Validity and utility of structural knowledge assessment. Journal of Business and Psychology, 18(2), 191-206.

Diana, L. (1993). Rethinking university teaching: A framework for the effective use of educational technology. London: Routledge.

Doyle, J. K., \& Ford, D. N. (1998). Mental models concepts for system dynamics research. System Dynamics Review, 14(1), 3-29.

Fein, R. M., Olson, G. M., \& Olson, J. S. (1993). A mental model can help with learning to operate a complex device. In Adjunct Proceedings of the Conference on Human Factors in Computing Systems (INTERACT'93) (pp. 157-158). New York, NY: ACM Press. 
Fung, J., Lau, A., \& Kai, S. (2003). Certificate computer and information technology elective module (A): Algorithm and programming. Hong Kong: Longman Hong Kong Education.

Geller, J., \& Dios, R. (1998). A low-tech, hands-on approach to teaching sorting algorithms to working students. Computers \& Education, 31(1), 89-103.

Gentner, D., \& Stevens, A. (1983). Mental models. Hillsdale, NJ: Erlbaum.

Goldsmith, T. E., Johnson, P. J., \& Acton, W. H. (1991). Assessing structural knowledge. Journal of Educational Psychology, 83(1), 88-96.

Greca, I. M., \& Moreira, M. A. (2000). Mental models, conceptual models, and modelling. International Journal of Science Education, 22(1), 1-11.

Gregorc, A. F. (1982). An adults guide to style. Columbia: Gregorc Associates, Inc.

Gregorc, A. F. (1984a). Gregorc style delineator: Development, technical and administration manual. Columbia: Gregorc Associates, Inc.

Gregorc, A. F. (1984b). Style as a symptom: A phenomenological perspective. Theory into Practice, 23(1), 51-55.

Hong Kong Curriculum Development Council. (2002). Personal, social \& humanities education key learning area curriculum guide (P1-S3). Hong Kong: HKSAR Government Printing Department.

Johnson-Laird, P. N. (1983). Mental Models. Cambridge, MA: Harvard University Press.

Johnson-Laird, P. N. (1989). Mental models. In M. I. Posner (Ed.), Foundations of Cognitive Science (pp. 469-499). Cambridge, MA: MIT Press.

Jonassen, D. H. (1995). Operationalizing mental models: Strategies for assessing mental models to support meaningful learning and design-supportive learning environments. In Proceedings of the Computer Support for Collaborative Learning (CSCL) Conference (pp. 182-162). Mahwah, NJ: Lawrence Erlbaum Associates.

Jonassen, D. H., Beissner, K., \& Yacci, M. (1993). Structural knowledge: Techniques for representing, conveying, and acquiring structural knowledge. Hillsdale, NJ: Lawrence Erlbaum Associates.

Jonassen, D. H., \& Grabowski, B. L. (1993). Handbook of individual differences, learning and instruction. Hillsdale, NJ: Lawrence Erlbaum Associates.

Joniak, A. J., \& Isaksen, S. G. (1988). The Gregorc Style Delineator: Internal consistency and its relationship to Kirton's Adaptive-Innovative distinction. Educational and Psychological Measurement, 48(4), 1043-1049.

Kordaki, M., Miatidis, M., \& Kapsampelis, G. (2008). A computer environment for beginners' learning of sorting algorithms: Design and pilot evaluation. Computers \& Education, 51(2), 708-723.

López, J., Myller, N., \& Sutinen, E. (2004). Sorting out sorting through concretization with robotics. In Proceedings of the working conference on Advanced visual interfaces (pp. 377-380). New York, NY: ACM Press.

Limón, M. (2001). On the cognitive conflict as an instructional strategy for conceptual change: a critical appraisal. Learning and Instruction, 11(4), 357-380.

Loo, R. (1997). Evaluating change and stability in learning style - a methodological concern. Educational Psychology, 17(1\&2), 95-100.

Ma, L., Ferguson, J., Roper, M., \& Wood, M. (2007). Investigating the viability of mental models held by novice programmers. SIGCSE Bulletin, 39(1), 499-503. 
McCaughtry, N. (2005). Elaborating pedagogical content knowledge: What it means to know students and think about teaching. Teachers and Teaching: theory and practice, 11(4), 379-395.

Messick, S. (1994). The matter of style: Manifestations of personality in cognition, learning, and teaching. Educational Psychologist, 29(3), 121-136.

Nash, J. G., Bravaco, R. J., \& Simonson, S. (2006). Assessing knowledge change in computer science. Computer Science Education, 16(1), 37 - 51.

Nichols, P. D. (1994). A framework for developing cognitively diagnostic assessment. Review of Educational Research, 64(4), 575-603.

O'Brien, T. P. (1990). Construct validation of the Gregorc Style Delineator: An application of LISREL 7. Educational and Psychological Measurement, 50, 631636.

Papastergiou, M. (2005). Students' mental models of the Internet and their didactical exploitation in informatics education. Education and Information Technologies, 10(4), 341-360.

Ramalingam, V., LaBelle, D., \& Wiedenbeck, S. (2004). Self-efficacy and mental models in learning to program. In Proceedings of the 9th annual SIGCSE conference on Innovation and technology in computer science education (pp. 171-175). New York, NY: ACM Press.

Reese, D. D. (2003). PFNET translation a tool for concept map quantification, Paper presented at the Annual Conference of the Association for Educational Communications and Technology. Anaheim, CA: Center for Educational Technologies, Wheeling Jesuit University.

Reeves, T. C. (2000). Alternative assessment approaches for online learning environments in higher education. Journal of Educational Computing Research, 23(1), 101-111.

Riding, R., \& Cheema, I. (1991). Cognitive styles - an overview and integration. Educational Psychology, 11(3/4), 193-215.

Riding, R., \& Rayner, S. (1998). Cognitive styles and learning strategies: Understanding style differences in learning and behaviour. London: David Fulton Publishers.

Ross, J. L., Drysdale, M. T. B., \& Schulz, R. A. (2001). Cognitive learning styles and academic performance in two postsecondary computer application courses. Journal of Research on Computing in Education, 33(4), 400-412.

Sadler-Smith, E. (2001). The relationship between learning style and cognitive style. Personality and Individual Differences, 30(4), 609-616.

Sasse, M-A. (1991). How to t(r)ap user's mental models. In M. J. Tauber \& D. Ackerman (Eds.), Mental models and human-computer interaction, Vol. 2 (pp. 59-79). Amsterdam: Elsevier.

Schulz, R. A. (1993). Cognitive learning styles research and applications for professors and students, Paper presented at the Annual Conference on Teaching and Learning in Higher Education. Winnipeg, Manitoba, Canada.

Schvaneveldt, R. W. (1990). Pathfinder associative networks: Studies in knowledge organization. Norwood, NJ: Ablex Publishing.

Seidel, L., \& England, E. M. (1997). Gregorc's cognitive styles: Preferences for instructional and assessment techniques in college students. Paper presented at the Annual Convention of the American Psychological Association, Washington, DC, USA. 
Shih, Y. F., \& Alessi, S. M. (1993). Mental models and transfer of learning in computer programming. Journal of Research on Computing in Education, 26(2), 154-176.

Staggers, N., \& Norcio, A. F. (1993). Mental models: Concepts for human-computer interaction research. International Journal of Man-Machine Studies, 38(4), 587605.

Trumpower, D. L., \& Goldsmith, T. E. (2004). Structural enhancement of learning. Contemporary Educational Psychology, 29, 426-446.

Uzuntiryaki, E., \& Geban, Ö. (2005). Effect of conceptual change approach accompanied with concept mapping on understanding of solution concepts. Instructional Science, 33(4), 311-339.

Van Engers, T. (2001). Knowledge management: The role of mental models in business systems design. Unpublished $\mathrm{PhD}$ Thesis, Vrije Universiteit, Amsterdam, Netherlands.

Winslow, L. E. (1996). Programming pedagogy - A psychological overview. SIGCSE Bulletin, 28(3), 17-22.

Woo, M. H. C., Shiu, Y. C., \& Wang, B. S. K. (2003). Computer and information technology for HKCEE module A1: Algorithm and programming Using C. Hong Kong: Digital Vision Educational Publishing Company. 
Table 1

Predictive validity of the similarity measure $\mathrm{C}$ of different experts

\begin{tabular}{cccccccc}
\hline & EXP1_C & EXP2_C & EXP3_C & AVE12_C & AVE23_C & AVE13_C & AVE123_C \\
\hline DK & 0.05 & $0.18^{*}$ & -0.05 & 0.10 & -0.04 & 0.05 & 0.10 \\
PK & $0.22^{*}$ & $0.20^{*}$ & 0.15 & 0.10 & 0.11 & $0.20^{*}$ & 0.17 \\
CK & 0.12 & $0.26^{* *}$ & $0.22^{*}$ & 0.10 & 0.16 & $0.25^{* *}$ & $0.20^{*}$ \\
SK & -0.11 & 0.10 & 0.08 & -0.01 & 0.10 & 0.11 & 0.08 \\
\hline
\end{tabular}

${ }^{*} \mathrm{p}<0.05 .{ }^{* *} \mathrm{p}<0.01$. 
Table 2

PRX, C and GTD by gender and learning style

\begin{tabular}{ccccccc}
\hline & \multicolumn{3}{c}{ Male } & \multicolumn{3}{c}{ Female } \\
\cline { 2 - 7 } & PRX & C & GTD & PRX & C & GTD \\
\hline CS & 0.48 & 0.27 & -0.01 & 0.70 & 0.24 & 0.06 \\
AS & 0.27 & 0.24 & 0.24 & 0.42 & 0.24 & 0.10 \\
CR & 0.71 & 0.19 & 0.03 & 0.40 & 0.19 & -0.13 \\
AR & 0.21 & 0.24 & 0.19 & 0.51 & 0.17 & -0.13 \\
\hline
\end{tabular}


Table 3

Means and standard deviations of similarity measures by gender and the perception dimension

\begin{tabular}{|c|c|c|c|c|c|c|c|c|c|c|c|c|}
\hline \multicolumn{5}{|c|}{ Female } & \multirow{2}{*}{\multicolumn{6}{|c|}{ Male }} & \multirow{2}{*}{\multicolumn{2}{|c|}{$\begin{array}{l}\text { Sub Total/ } \\
\text { Grand Total }\end{array}$}} \\
\hline & & & & & & & & & & & & \\
\hline & $\begin{array}{l}\text { Perception } \\
\text { Type }\end{array}$ & $\mathrm{N}$ & Mean & S.D. & & $\begin{array}{l}\text { Perception } \\
\text { Type }\end{array}$ & $\mathrm{N}$ & Mean & S.D. & $\mathrm{N}$ & Mean & S.D. \\
\hline \multirow[t]{3}{*}{ PRX } & Concrete & 23 & 0.272 & 0.261 & PRX & Concrete & 56 & 0.166 & 0.222 & 79 & 0.197 & 0.237 \\
\hline & Abstract & 28 & 0.162 & 0.236 & & Abstract & 23 & 0.063 & 0.217 & 51 & 0.117 & 0.231 \\
\hline & Sub Total & 51 & 0.212 & 0.252 & & Sub Total & 79 & 0.136 & 0.224 & 130 & 0.166 & 0.237 \\
\hline \multirow[t]{3}{*}{$\mathrm{C}$} & Concrete & 23 & 0.317 & 0.141 & $\mathrm{C}$ & Concrete & 56 & 0.255 & 0.107 & 79 & 0.273 & 0.120 \\
\hline & Abstract & 28 & 0.273 & 0.109 & & Abstract & 23 & 0.221 & 0.104 & 51 & 0.250 & 0.109 \\
\hline & Sub Total & 51 & 0.293 & 0.125 & & Sub Total & 79 & 0.245 & 0.107 & 130 & 0.264 & 0.116 \\
\hline \multirow[t]{3}{*}{ GTD } & Concrete & 23 & 0.221 & 0.206 & GTD & Concrete & 56 & 0.091 & 0.193 & 79 & 0.129 & 0.205 \\
\hline & Abstract & 28 & 0.076 & 0.199 & & Abstract & 23 & -0.003 & 0.230 & 51 & 0.041 & 0.215 \\
\hline & Sub Total & 51 & 0.141 & 0.213 & & Sub Total & 79 & 0.063 & 0.208 & 130 & 0.094 & 0.213 \\
\hline
\end{tabular}


Table 4

A MANOVA table $(n=130)$

\begin{tabular}{lrrrr}
\hline Source & df & F & Partial $\eta^{2}$ & \multicolumn{1}{l}{ p } \\
\hline Gender & 3 & 2.748 & 0.062 & 0.046 \\
Perception Dimension & 3 & 3.558 & 0.079 & 0.016 \\
Gender $\times$ Perception Dimension & 3 & 0.310 & 0.007 & 0.818 \\
Error & 124 & & & \\
\hline
\end{tabular}


Table 5

Mis-defined concepts based on comparison of concepts with those of a single expert for males

\begin{tabular}{llll}
\hline CS & AS & CR & AR \\
\hline computer & & computer & computer \\
& program & program & program \\
& algorithm & & algorithm \\
& sorting & & \\
& & arrange \\
pass & porrect order & & correct order \\
& pass & pass & pass \\
& & & compare \\
descending & ascending & & swapping \\
\hline
\end{tabular}


Table 6

Mis-defined concepts based on comparison of concepts with those of a single expert for females

\begin{tabular}{llll}
\hline CS & AS & CR & AR \\
\hline computer & computer & computer & computer \\
program & program & program & program \\
& & algorithm \\
& sorting & sorting & sorting \\
& & \\
pass & correct order & pass & correct order \\
& pass & & pass \\
& & & swapping \\
& & ascending & ascending \\
\hline
\end{tabular}




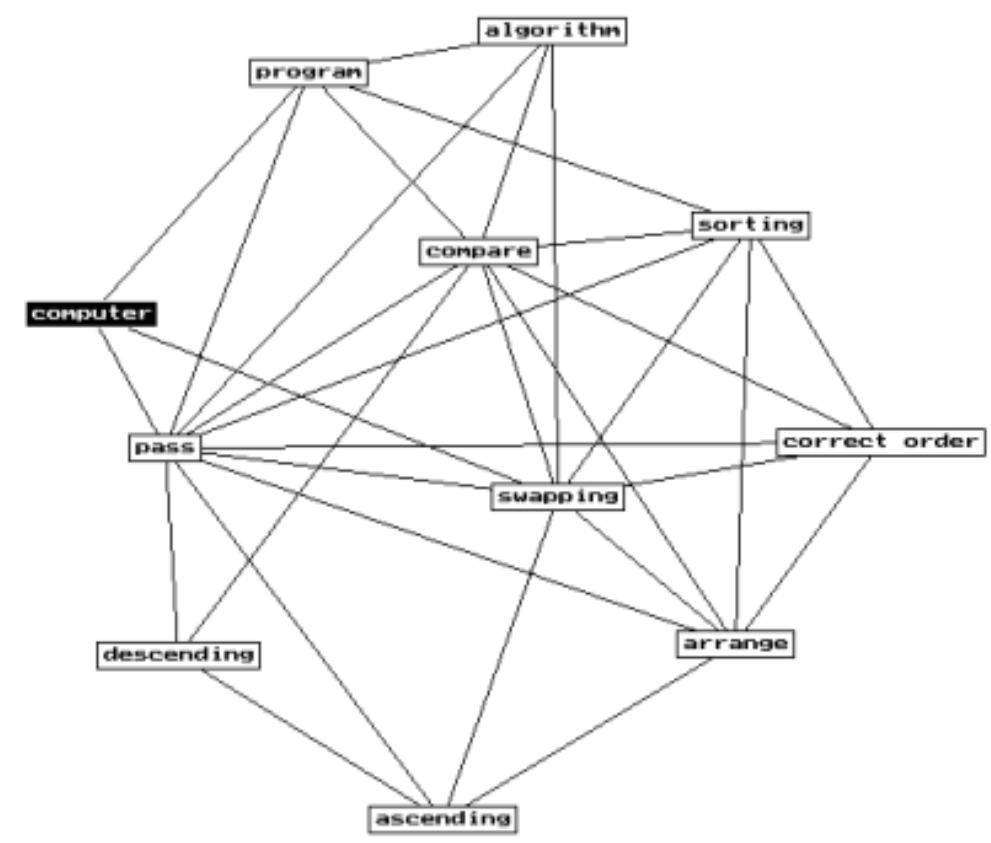

Fig. 1. PFNET by the expert 


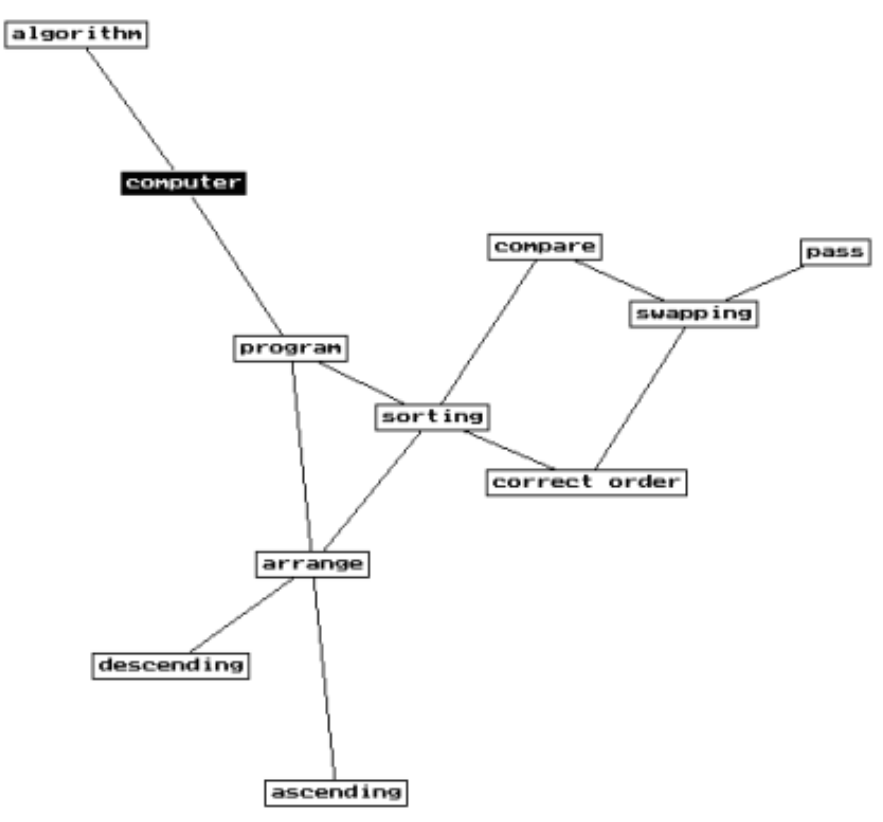

Fig. 2. PFNET by averaging the male $\mathrm{CS}$ group $(\mathrm{n}=23)$ 


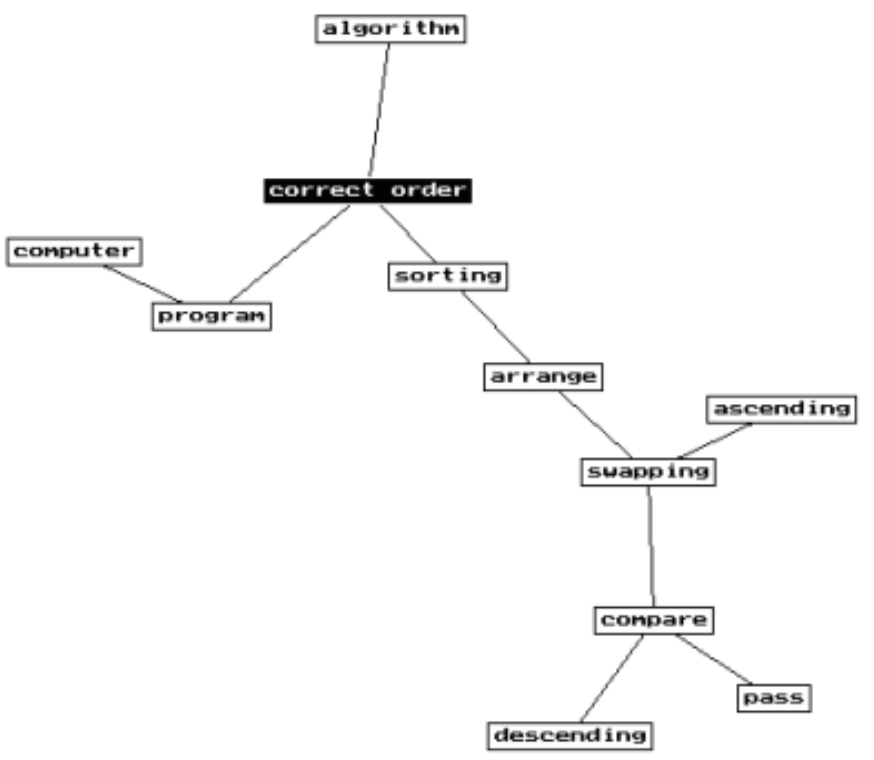

Fig. 3. PFNET by averaging the male AS group $(n=12)$ 


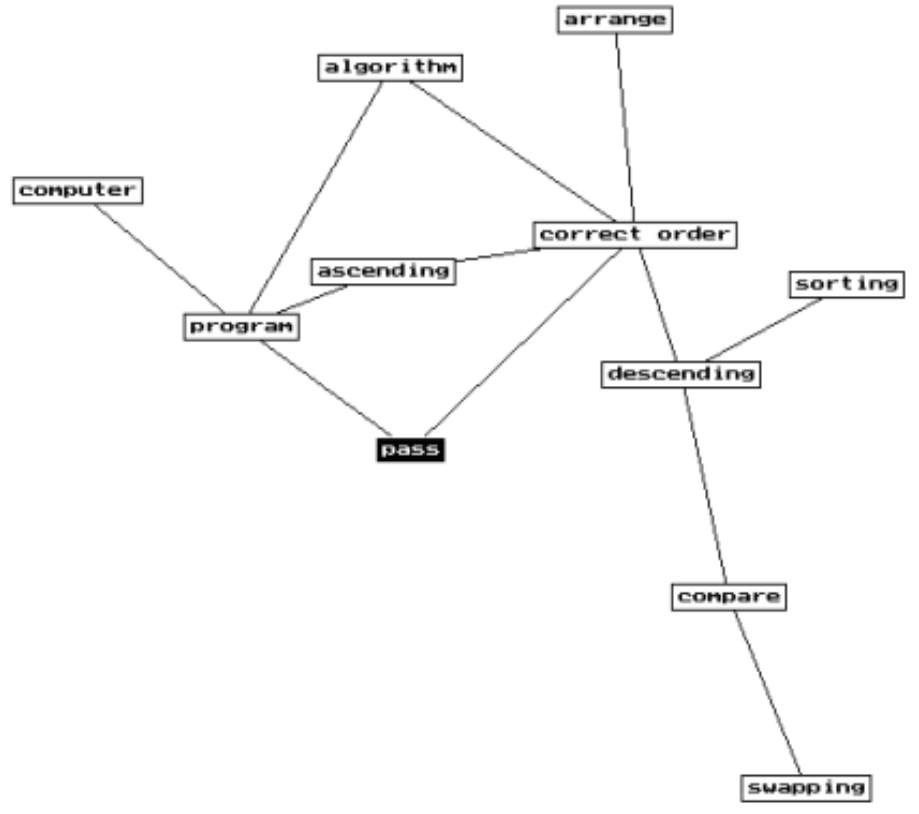

Fig. 4. PFNET by averaging the male CR group $(n=33)$ 


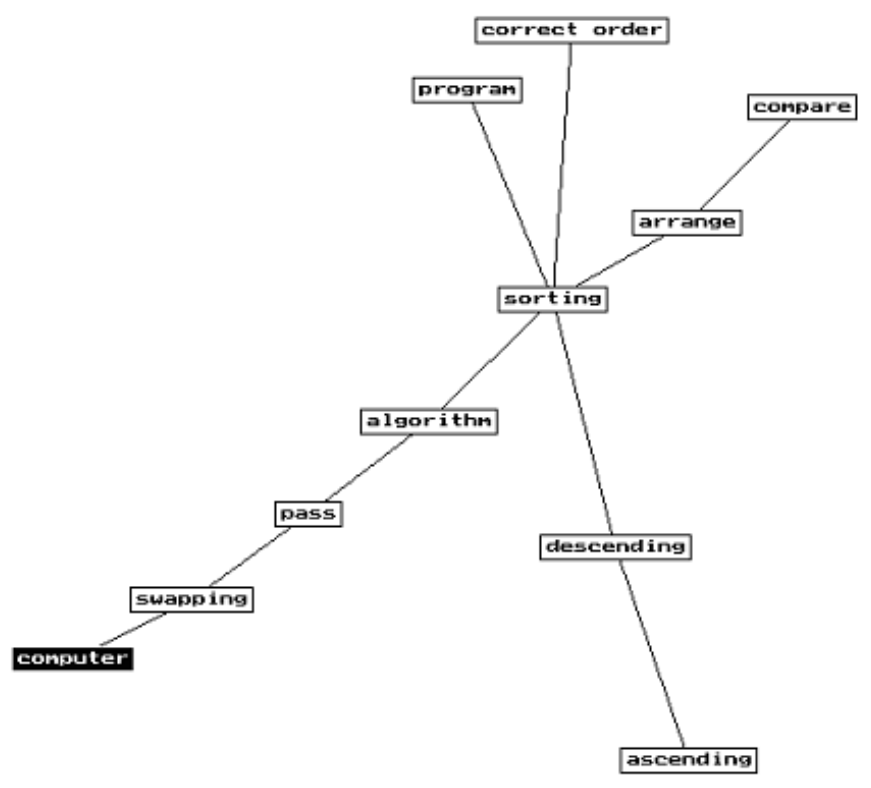

Fig. 5. PFNET by averaging the male AR group $(n=11)$ 


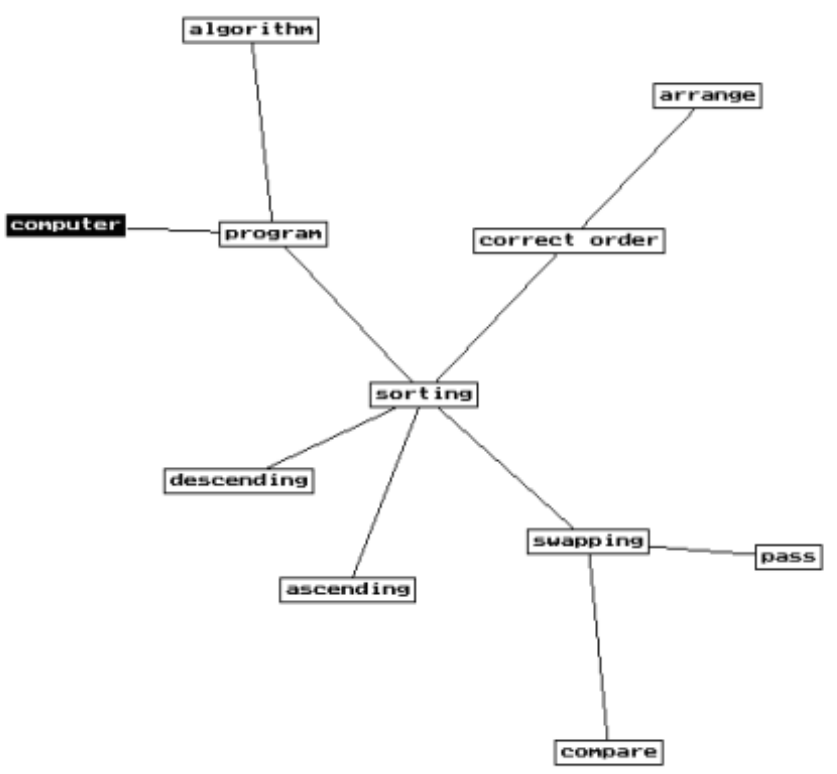

Fig. 6. PFNET by averaging the female CS group $(\mathrm{n}=18)$ 


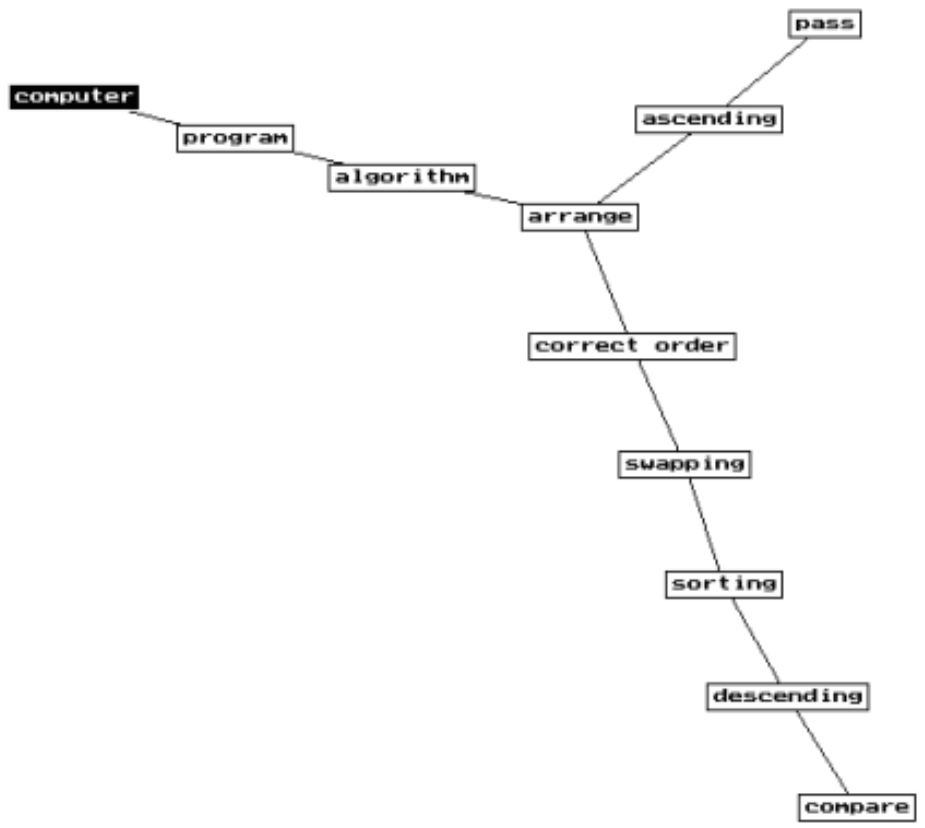

Fig. 7. PFNET by averaging the female AS group $(n=16)$ 


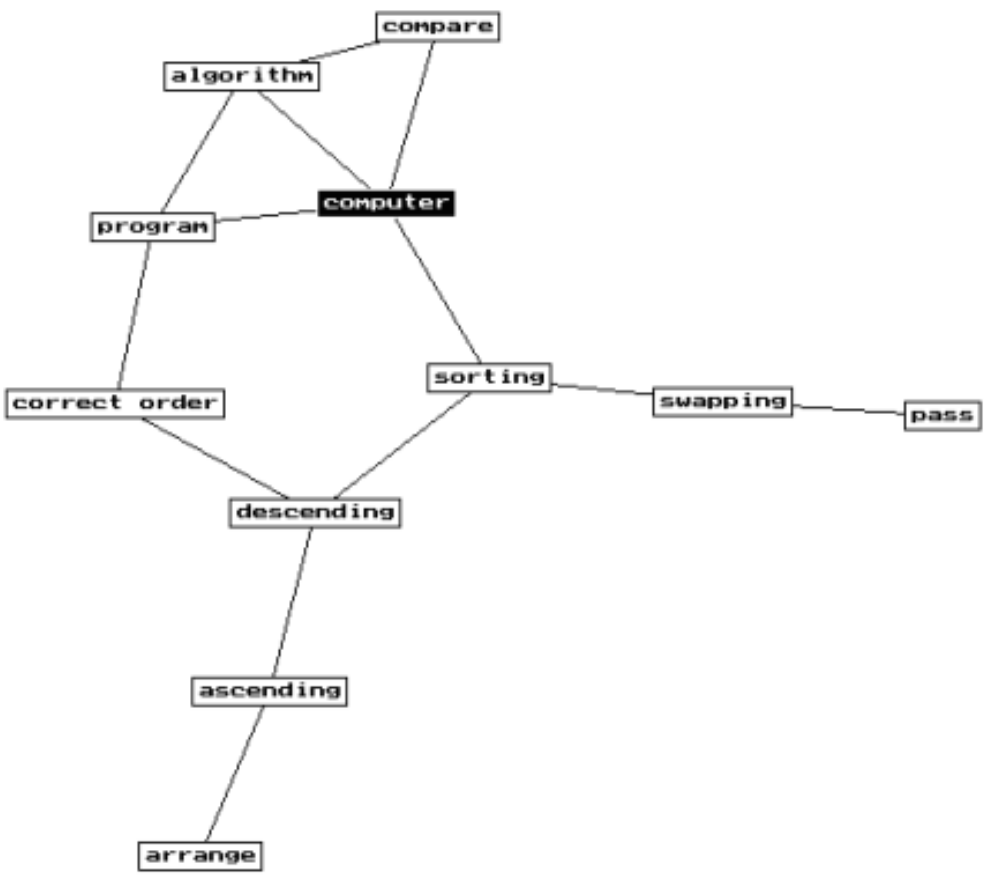

Fig. 8. PFNET by averaging the female $\mathrm{CR}$ group $(\mathrm{n}=5)$ 


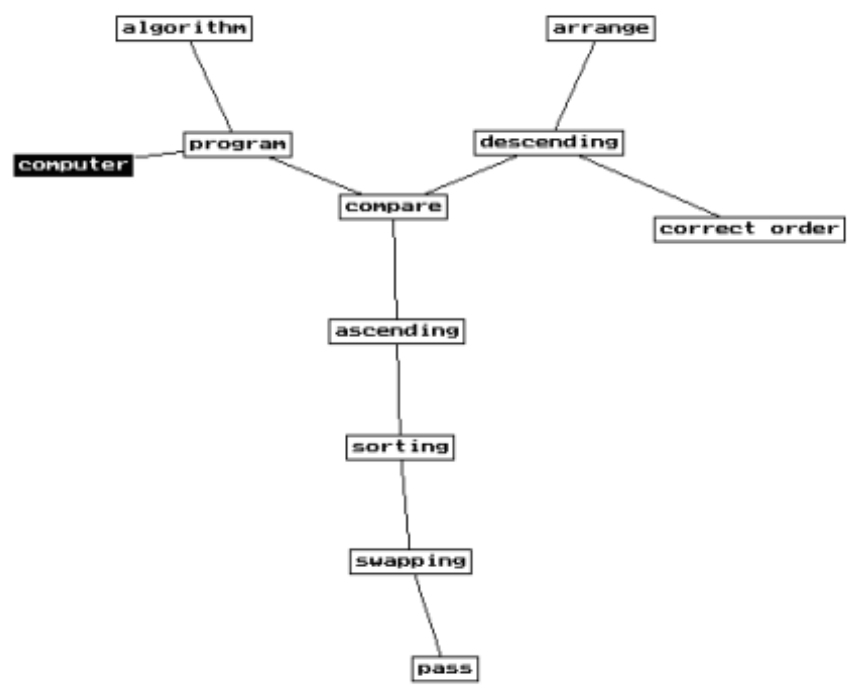

Fig. 9. PFNET by averaging the female AR group $(n=12)$ 